\title{
The Non-identity Problem and the Psychological Account of Personal Identity
}

\section{Bruce P. Blackshaw ${ }^{1}$}

Received: 4 September 2020 / Accepted: 26 July 2021 /

Published online: 13 August 2021

(c) The Author(s) 2021

\begin{abstract}
According to the psychological account of personal identity, our identity is based on the continuity of psychological connections, and so we do not begin to exist until these are possible, some months after conception. This entails the psychological account faces a challenge from the non-identity problem-our intuition that someone cannot be harmed by actions that are responsible for their existence, even if these actions seem clearly to cause them harm. It is usually discussed with regard to preconception harms, but in the context of the psychological account, it is also applicable to prenatal harms. Inflicting prenatal injury is widely thought to be morally impermissible, but if the injury is identity-determining on the psychological account, then no-one seems to be harmed-rather, the injury is responsible for bringing them into existence. Here, I argue that identity-determining injuries can routinely occur on the psychological account, and that this undermines the account. I assess Nicola Williams' proposal to salvage the account based on a trans-world account of personal identity, and show that it is unsuccessful. I then show that Jeff McMahan's embodied mind account of personal identity is also susceptible. I conclude that identity-determining prenatal injuries pose a significant challenge for the psychological account and its variants, and provide a reason for supporting alternative accounts that fix personal identity at conception.
\end{abstract}

Keywords Non-identity problem $\cdot$ Personal identity $\cdot$ Prenatal injury $\cdot$ Psychological accounts $\cdot$ Embodied mind account

\section{Introduction}

According to the psychological account of personal identity, our identity is based on the continuity of psychological connections, and we do not begin to exist until these are possible, some months after conception. This delay in fixing our identity exposes

Bruce P. Blackshaw

bblackshaw@gmail.com

1 Department of Philosophy, University of Birmingham, Birmingham, UK 
the psychological account faces a challenge from the non-identity problem-a paradox about future people, based on our intuition that someone cannot be harmed by actions that are responsible for their existence, even if these actions seem to cause them harm.

Traditionally, the non-identity problem is discussed in relation to preconception harms that, if they did not occur, would mean the person they seemed to harm would not exist-for example, parents who choose to conceive a child that will inherit a serious genetic disorder. The psychological account of personal identity, because it claims we come into existence some time after our physical organism begins to exist, creates a new category of non-identity problems: scenarios involving prenatal injury that is identity-determining. If such injury causes a different psychological individual to exist than would have if the injury had not occurred, then the nonidentity problem comes into play. The implication is that such an individual cannot have been wronged, as without the injury they would not have come into existence. However, our intuition that it is wrong to deliberately injure a fetus is strong and not dissimilar to the strength of our intuition regarding the wrong of deliberately harming persons - and it seems stronger than our intuitions regarding the wrongs involved in more traditional non-identity cases such as that described above. If such injuries are possible, this undermines the cogency of the psychological account of personal identity.

Here, I argue that identity-determining prenatal and neonatal injury can and do occur on the psychological account of personal identity. I show that Nicola Williams' proposal to salvage the psychological account based on a trans-world account of personal identity is unsuccessful. Finally, I briefly examine Jeff McMahan's embodied mind account of personal identity, showing that although such identitydetermining injuries are less likely to occur, it remains susceptible. I conclude that identity-determining prenatal and neonatal injury is a significant weakness for the psychological account of personal identity and its variants, and provides support for alternative accounts that fix personal identity from conception.

\section{The Non-identity Problem}

The non-identity problem is widely known by its presentation by Derek Parfit in Reasons and Persons (1987), and is best explained by illustration. Suppose a couple have been advised that because of a temporary medical condition, if they conceive a child now, their baby will be born with a serious disability, but if they delay by a few months, their baby will not have this disability. Intuitively, to conceive now seems wrong, because the parents would be choosing for their child to be seriously disabled. However, if taken this choice will be responsible for this particular child existing. In later years, the disabled child could not claim that, if her parents had waited, she would not be disabled. If the parents had done so, she would not exist. The nondisabled child would be a different person. This is the paradox of the non-identity problem: a comparison cannot be made between the life of a person with the disability, and the same person without the disability: without the actions that resulted in the disability, that person would not exist. Intuitively, it seems that the person with 
the disability has been harmed, but because our conception of harm is comparative and there are no circumstances under which she would exist without the disability, it seems that no-one is harmed.

The non-identity problem, then, is a problem arising from a clash of our moral intuitions. One intuition is what Parfit calls a person-affecting principle of morality (1987, p. 370) — that acts are wrong only if they make things worse for a person. A related intuition is that acts that confer existence on persons cannot make things worse for those persons. The final intuition is that certain acts are wrong, resulting in a world that seems obviously worse than if the acts had not been committed, even though they do not make things worse for specific people. To solve the non-identity problem, these intuitions must somehow be reconciled.

One solution is to reject person-affecting moral principles of harm in favour of some form of impersonal consequentialist principle, or what Parfit calls Theory X. For example, classical utilitarians can avoid the non-identity problem because they judge acts based on their contribution to well-being, aggregated across populations. Parfit rejects this approach because it is difficult to avoid what he calls the repugnant conclusion: it implies that for any given population with a very high quality of life, there is always a much larger population that would have greater aggregated well-being, even though each member would have a life barely worth living. David Boonin similarly rejects consequentialism as a solution, arguing that it drastically 'departs from common-sense moral beliefs' (2008).

There are various other approaches to solving the non-identity problem. One solution is to develop an account of personal identity that entails a specific person is harmed in non-identity scenarios. Another is to offer a non-comparative personaffecting principle that regards bringing a person into a suboptimal existence as harmful, even though no other existence is possible. In his book-length treatment of the non-identity problem, Boonin considers a comprehensive range of options in considerable detail, and rejects them all, embracing what he calls the implausible conclusion - that these acts in non-identity scenarios are not morally wrong, despite our intuitions to the contrary (2014, p. 189).

\section{The Psychological Account of Personal Identity}

Clearly, the central aspect of the non-identity problem is the concept of personal identity. Since the non-identity problem involves changing which future person will exist, then it is crucial to know what determines the identity of future persons, and how sensitive personal identity is to changes in preconditions.

The psychological account of personal identity is widely supported. ${ }^{1}$ According to the psychological account, we are essentially psychological beings, and we do not come into existence until a considerable time after conception. Derek Parfit (1987, pp. 199-217) provides the most widely accepted psychological account, defining

\footnotetext{
1 According to the PhilPapers survey, a third of respondents nominated the psychological view of personal identity, almost double the number who chose the biological view (Bourget \& Chalmers 2014).
} 
identity as psychological continuity. He defines two important relations: psychological connectedness is 'the holding of particular direct psychological connections', while psychological continuity is 'the holding of overlapping chains of strong connectedness'. Strong connectedness is defined to be when the number of direct connections that hold are at least half of the number of direct connections that hold for every actual person.

In his description of the psychological account, Jeff McMahan provides some examples of psychological connections: 'the relation between an experience and a memory of it, the relation between the formation of a desire and the experience of satisfaction or frustration of that desire, and the relation between an earlier and a later manifestation of a belief, value, intention, or character trait' (2002, p. 39). The requirement for strong psychological connections from day to day implies that selfconsciousness is a requirement for us to exist, and so on the psychological account, we do not come into existence until we become self-conscious, some months or years after birth. Prior to this point, fetuses and infants lack sufficient psychological connections to be strongly connected from day to day. Put another way, on this account we are essentially persons, where a person is a self-conscious entity. In terms of persons, Parfit's account of identity states that a person $\mathrm{X}$ today is the same person as $\mathrm{Y}$ at a past time if and only if $\mathrm{X}$ is psychologically continuous with $\mathrm{Y}$ and the continuity is non-branching. The non-branching restriction is required for the identity relation, to prevent replication cases and consequently a person being identical to several persons. Also, Parfit stipulates that psychological continuity must have the right kind of cause. For example, a memory of an experience that is actually the result of someone else recounting the experience would not be regarded as the right kind of cause. Parfit's 'narrow' version of his psychological account requires the continued existence and functioning of the same brain as the normal cause of psychological connections.

\section{Identity-Determining Injury}

If we are essentially psychological beings, coming into existence some time after our human organisms begin to exist, then clearly there is the possibility of identitydetermining prenatal (and even postnatal) injury being inflicted on the human organism that we will eventually occupy. If such an injury is inflicted on a fetus or neonate, Boonin's approach to traditional non-identity problems-accepting that such acts are not morally wrong-seems untenable. All deliberately inflicted prenatal injury seems indubitably wrong - it has long been recognised that children have the right to compensation for prenatal injuries inflicted upon them. In the United Kingdom, the Congenital Disabilities (Civil Liability) Act 1976 enables a child to sue for damages for prenatal injury caused by someone other than their mother (1976). It seems absurd to claim that a particular category of injuries- those that are identitydetermining - do not harm the individual (who only exists because of the injury), and yet there seems no other plausible conclusion if the psychological account is accepted. 
This raises the question of what prenatal and neonatal injuries are potentially identity-determining. For Parfit's psychological account, this is not clear, as personal identity is framed in terms of continuity of psychological connections. This approach is taken to answer the persistence questions of personal identity-how an individual can remain the same entity from one time to another. However, psychological continuity is of no value when evaluating if contingent future persons should be regarded as being the same person-it is impossible for different contingent future persons to be psychologically connected in any way. Instead, we need to know what characteristics are essential to our identities. Clark Wolf (2009) captures this in his Identity Principle (IP):

If characteristics $\mathrm{C}$ are identity-determining for person $\mathrm{P}$, then any child born with characteristics different from $\mathrm{C}$ would have been a different person from $\mathrm{P}$ (even if all other characteristics were the same).

Parfit discusses identity-determining scenarios, acknowledging our identity's dependence on our biological origins in his revised Time-Dependence Claim (TDC): 'if any particular person had not been conceived within a month of the time when he was in fact conceived, he would in fact never have existed' (1987, p. 352). In Parfit's view, then, a zygote produced from different germ cells (both ovum and sperm) will result in a different person. This seems an uncontroversial claim, but presumably this holds on the psychological account of identity because different psychologies are generated by different brains. In turn, this suggests prenatal injury that produces comparable differences in the brain to that produced by a significantly different genome may also be identity-determining. The TDC also suggests the possibility of prenatal injury involving significant genetic manipulation, altering our biological origins and giving rise to a different person.

Nicola Williams suggests that there are other possibilities for identity-determining changes under psychological accounts. She claims that our genetic code is the 'origin of a potential myriad of other potential persons who may or may not have come to exist had things turned out differently, depending upon how the genetic determinants of their identities were shaped and influenced by environmental factors' (Williams, 2013). Williams gives some examples of potential Nicolas that she believes would be different persons: Russian Nicola (raised in Russia), Actual Nicola and Intellectually Disabled Nicola, who is disabled by injury (2013).

It is doubtful whether all Williams' examples constitute different possible persons under Parfit's account. Parfit explicitly states that if he had moved to Italy when he was three years old, although his life would have been very different, this could still be regarded as identity (1987, note 6 part 4). Clearly, however, Parfit's TDC implies prenatal identity-determining injury is certainly a realistic possibility on the psychological account of identity.

If we utilise Wolf's IP, what characteristics $\mathrm{C}$ are likely to be identity-determining? Wolf reasonably claims that 'minor perturbations' in $\mathrm{C}$ are unlikely to change our identities: our identities may be vague, and quite radical changes in $\mathrm{C}$ may be required to conclude that a different person exists from the person that would have existed. Given the central importance of psychological connections to personal identity under the psychological account, it is clear that our psychological connections 
are the characteristics $\mathrm{C}$ that determine our psychological identities. Consequently, physical changes $\mathrm{P}$ that result in radically different $\mathrm{C}$ will be identity-determining.

We have already listed McMahan's examples of psychological connections, which I repeat once more for reference: 'the relation between an experience and a memory of it, the relation between the formation of a desire and the experience of satisfaction or frustration of that desire, and the relation between an earlier and a later manifestation of a belief, value, intention, or character trait' (2002, p. 39). To determine what $\mathrm{P}$ will produce $\mathrm{C}$, we must consider what changes $\mathrm{P}$ would result in substantially different psychological connections.

If we take a conservative view such as Parfit's and assume that being brought up in a different country (say Italy rather than the United Kingdom) does not change someone's personal identity, we are conceding that developing different memories does not necessarily entail a change of identity. Such a person's family will be the same, but they will live in a different environment and culture, and speak a different language. It might even be that they are living with a relative rather than their immediate family, and so their experiences will be almost entirely different. Our memories, therefore, are contingent on our circumstances and can vary a great deal without apparently changing our identity. This, however, makes it difficult to decide what characteristics are identity-determining. It seems that all of our memories could be different, and yet we could be regarded as the same individual. Moreover, twins, at least for a time, will accrue almost identical memories, and yet are clearly different individuals.

At the most fundamental level, we could distinguish different individuals by their different brains, and yet it seems inconsistent to solely do so on the psychological account-if continuity of psychological connections defines an existing individual, they must be relevant to the formation of an individual. I propose, therefore, that identity-determining characteristics are those characteristics that bear on the formation process for the psychological entities that participate in our psychological connections-our memories, experiences, desires and beliefs. If these characteristics are damaged or altered to the extent that they are no longer capable of producing the same psychological entities, then the damage is identity-determining. Primarily, these characteristics are our perceptual abilities (visual, auditory, motor skills, etc.) and our cognitive abilities (use of learned knowledge, problem solving, verbal memory, visual memory, processing speed etc.). These two groups of abilities are closely linked-cognitive processes rely on perceptual information, while cognitive information influences perception processes (Tacca, 2011).

Any physical change $\mathrm{P}$ that modifies our perceptual and cognitive abilities to a substantial extent is potentially an identity-determining change. For an adult with many established psychological connections, $\mathrm{P}$ is not likely to change their identity, but if $\mathrm{P}$ occurs prior to any psychological connections being formed, very different connections will develop. These cannot be the connections that would have formed had $\mathrm{P}$ not occurred, and hence a different psychological individual will result. For example, if prior to birth $\mathrm{P}$ caused profound intellectual disability or blindness and deafness to a fetus, they would be unable to have the same experiences, would not be capable of forming the same beliefs and values, and would have a completely different set of memories. They would be a different 
psychological individual compared to what they would have been without P. Of course, the boundary between physical changes that are not identity-determining and those that are is undoubtedly vague, and many changes may be indeterminate with regard to their effect on identity. Nonetheless, it is clear that certain changes will result in a change of identity.

Finally, the most important cognitive faculty is consciousness. If, instead of developing a normal level of consciousness, we instead attained only a minimally conscious state with extremely limited awareness, under the psychological account the same person could not eventuate. If a body never reaches consciousness, on the psychological account of identity, no person inhabits it. This latter case is no longer a non-identity problem, but it is still a reductio for the psychological account-Rodger, Blackshaw and Miller argue that it entails that it would be permissible to prevent consciousness from arising in infants in order to provide a supply of transplant organs in order to benefit persons and other heinous actions (2018).

We now can suggest some realistic scenarios that could result in identity-determining changes inflicted upon fetuses and infants. Fetal alcohol syndrome is one example. It causes permanent brain damage, resulting in intellectual impairment, and learning and behaviour disabilities (Wilhoit et al., 2017). Another possibility for neonates is abusive head trauma - a follow-up of infants some years after their injuries found that $40 \%$ suffered severe neurological impairment, and $30 \%$ required special education services (Lind et al., 2016). Severe cases of fetal alcohol syndrome and abusive head trauma can therefore result in significant intellectual impairment, resulting in the formation of very different memories and beliefs. I conclude that on the psychological account of personal identity, identity-determining injuries on fetuses and neonates are not only possible, but occur relatively frequently.

\section{Possible Responses to Identity-Determining Injury}

According to Boonin (2014, p. 189) we must embrace the implausible conclusion that the acts in traditional non-identity scenarios are not morally wrong, even though we have strong intuitions to the contrary. Perhaps this is possible for these traditional scenarios, but to conclude that deliberately inflicting fetal alcohol syndrome on a fetus or severe abuse head trauma on a neonate is not morally wrong seems untenable rather than implausible. This forces us to acknowledge that the psychological account of personal identity is inadequate, and we must investigate modifications or alternative accounts that are better able to cope with identity-determining prenatal and postnatal injuries. I will now examine two alternative accounts of personal identity that offer a potential solution and yet retain a commitment to the importance of psychological connectedness and continuity for personal identity. The first is offered by Nicola Williams, and is based on counterparts; the second is McMahan's embodied mind account of personal identity. 


\section{Trans-world Psychological Identity}

In an attempt to avoid the non-identity issues associated with prenatal injury, Williams (2013) proposes an account of trans-world identity based on the psychological account of personal identity. It involves a relaxation of the criteria for identity across possible worlds, with the intention of preserving identity in cases of prenatal injury. If this can be shown to be viable, then we can preserve our person-affecting moral principle. Williams' proposal involves the use of David Lewis' modal realism to define trans-world identity via counterpart relations, as explored by Wrigley (2012) and Meacham (2012) as a potential pathway to solutions for traditional non-identity problems.

Lewis (1986, p. 2) holds that all possible worlds are real in the way our world is real. Worlds are isolated-individuals can exist only in one world and there is no such thing as trans-world identity. Modal predications about an individual are made using counterparts in other possible worlds. Our counterparts closely resemble usthey are as we would have been if the world had been otherwise. The counterpart relation is a relation of similarity, and serves as a substitute for identity across possible worlds. A crucial requirement of any account of trans-world identity based on counterpart theory is to determine what similarity relations are to be employed. Lewis explains that context is the primary consideration for choosing counterpart relations: 'the limits of the range are subject to pressures of context. Two things may be counterparts in one context, but not in another' (1986, p. 254).

For her trans-world psychological account, Williams suggests two similarity relations be employed. The first, which she calls 'branching counterpart relations', is based on sharing a common psychology: an individual's counterparts are all the persons across possible worlds that have branched from their psychology (2013). The second similarity relation is that of sharing a distinct genome, which Williams calls 'genetic counterpart relations'. Using these two relations, Williams believes we can account for prenatal injury in terms of harm under a psychological account of persons: "where it is the case that two numerical persons ( $x$ and $y$ ) share a branching/genetic counterpart relation and $\mathrm{x}$ is better off than $\mathrm{y}$ as a result of a particular course of action taken by another, we can state that in being $x$ 's counterpart y is harmed by this action' (2013).

Let us consider Williams' account in the scenarios described above-fetal alcohol syndrome and severe abusive head trauma. Clearly, the genetic counterpart relation holds across possible worlds, as in all cases, whether prenatal injury has been inflicted or not, the fetus shares the same genome. Williams' branching counterpart relation is more problematic. According to Williams, a shared psychological history means counterparts must 'share a common psychology, whether it be linear or branched' (2013). However, in our two scenarios, we have concluded that in these cases there is no shared psychological history-the characteristics $\mathrm{C}$ produced by the physical changes $\mathrm{P}$ are identity-determining on the psychological account, and so a fetus in these scenarios will develop a radically different set of psychological connections than it would have otherwise. Accordingly, the branching counterpart relation will not hold in these scenarios. 
In effect, we have the same difficulty as with the psychological account: if prenatal injury is identity-determining on a psychological account in our world, the branching relation will not hold trans-world. If Williams requires both counterpart relations for her trans-world identity account, then trans-world identity does not hold in our scenarios - they are identity-determining and the problem of explaining the wrongness of severe prenatal (and neonatal) injury remains because of the non-identity problem. If Williams only requires either of the branching and genetic counterpart relations to hold, then trans-world identity does hold, and the wrongness of severe prenatal injury is explained. In doing so, however, the branching relation is superfluous, and she is left with the genetic counterpart relation. Her account has collapsed into a biological account of identity in which we are essentially human organisms. This is no longer a psychological account of personal identity.

There is another important issue with Williams' account, which Boonin highlights. He identifies a number of constraints that a reason should satisfy for rejecting one of the premises of the non-identity problem, one of which is the independence requirement-there should be a justification for adopting this reason that is independent of its ability to avoid the non-identity problem (2014, p. 20). Boonin criticises Meacham's counterpart solution for failing to meet the independence requirement, referring to a thought experiment involving Wilma, who, if she waits two months to conceive, will have a child who is not blind. He states that 'Meacham provides no reason to think this is the appropriate counterpart relation to use when thinking about such situations morally other than the fact that if we do so, we get the result that Wilma's act is morally wrong' (2014, p. 40). Williams' counterpart relations suffer the same difficulty - there is no reason to adopt them other than their potential usefulness in solving the non-identity problem, and so Boonin's independence requirement is not met, even if we were to concede Williams' account succeeds. It is clear, then, that Williams' account is not successful in resolving the nonidentity problem for prenatal and neonatal injury.

\section{The Embodied Mind Account}

There is an alternative account of personal identity that maintains the centrality of psychological continuity, but also recognises the importance of the physical basis for our psychology, the brain-McMahan's embodied mind account. This account is based on the intuition that our egoistic concern about our future is primarily based on continuity of our consciousness, and this requires physical and functional continuity of our brains (McMahan, 2002, p. 67). Importantly, McMahan stresses that his account does not require continuity of psychological connections-we can survive both the deprogramming of our brains, and the progression of Alzheimer's disease until our capacity for consciousness disappears. This means the scope for identitydetermining prenatal injury is significantly more limited than with the psychological account. However, McMahan is clear that identity-determining changes are possible, stating that 'a radical alteration of the structures of the developing embryonic brain might cause a different child to exist from the one who would have existed in the absence of the alteration' (2005). Presumably, the alterations must be sufficient 
to disrupt the development of the functional integrity of the brain, particularly the regions that realise consciousness, but it is unclear the extent of alterations required.

McMahan does directly address the issue of prenatal injury, citing the scenario of a pregnant woman taking a drug that will make the fetus infertile in later life, and noting that it is widely believed such actions are seriously wrong (2002, p. 280). A central element of McMahan's account is the concept of time-relative interests: an individual's interests at a particular time relativised by the degree of psychological unity they possess. Psychological unity of a mind between two different times is a function of the degree of psychological connectedness that is maintained over the period, including the number of psychological connections and the richness of mental life. Time-relative interests diverge from actual interests when an entity's psychological unity is weak, so a fetus, whilst having a strong interest in continuing to live, has a weak time-relative interest in continuing to live because of its non-existent or low degree of psychological unity. This is how McMahan grounds the permissibility of abortion, by arguing that his account better explains why killing persons is worse than killing fetuses than a harm-based account does. How does this work with prenatal injury, given a fetus also has a weak time-relative interest in avoiding injury? McMahan explains that all time-relative interests must be taken into account, both present and future. The fetus has much stronger time-relative interests as an adult, and so this entails prenatal injury is wrong because it damages these interests. By contrast, the aborted fetus has no future interests as they are prevented from arising, and its overall weak time-relative interests are easily overridden by the interests of actual persons.

If the fetus has not yet sufficiently developed to have an embodied mind, it has no time-relative interests-it does not possess identity-determining potential. However, McMahan notes that our present actions are constrained by their effects on future individuals that may not yet exist, and as prenatal injury affects the future time-relative interests of an individual, it is still immoral (McMahan, 2006).

However, McMahan does not address cases of identity-determining prenatal injury. Because McMahan's account is not purely psychological, it requires very serious injuries that radically change the structure of the brain for them to be identity-determining - but they are still possible, as I have noted. Although the fetus's future time-relative interests are clearly affected compared to what they would have been, without such injuries the ensuing individual would not exist, and so the problem of deciding how it is harmed remains. In fact, the problem is more acute, because while most prenatal injuries are clearly harmful, very serious injuries are not, which seems absurd.

\section{Other Alternative Accounts}

There are alternatives to psychological accounts of personal identity that are not susceptible to the non-identity problem for prenatal injury. These include all accounts of personal identity where an individual's identity is fixed at conception, meaning there is no possibility of prior prenatal injury. Examples include animalism - the view that we are essentially human organisms-and the substance view of persons, 
which regards human beings as Aristotelian substances that maintain their identity through change. Views that we are essentially souls such as substance dualism are also not susceptible to this issue. In all these views, the individual's identity is already determined before prenatal injury can be inflicted.

I am not arguing for a particular account here, but rather am highlighting an important issue for the psychological account of personal identity and McMahan's embodied mind account. It is a puzzle explaining identity-determining injuries on these accounts, and the puzzle is easily resolved by adopting an account that fixes identity at conception. Therefore, this issue should be considered a strong point in favour of such accounts, and a major point of weakness for psychological accounts.

\section{Conclusion}

The non-identity problem challenges our intuitions about what it means for a person to be harmed. Traditional non-identity scenarios involve preconception identitydetermining changes, but I have shown that under the psychological account of personal identity, certain severe prenatal injuries can also be identity-determining and are likely to occur regularly. It is extremely implausible to accept that deliberately inflicting such injuries is not deeply wrong, especially when less serious prenatal injuries are uncontroversially regarded as wrong, and so we are forced to explore other accounts of personal identity in order to explain this conundrum.

I first examined Williams' proposal to use Lewis' modal realism to come to grips with the non-identity problem for prenatal injury by employing counterpart relations to construct a trans-world account of personal identity. I have shown that this does not succeed: if prenatal injury is identity-determining according to standard psychological accounts, it will also be identity-determining if it relies upon Williams' branching counterpart relation that utilises a shared psychological history. This cannot be avoided if the account of personal identity is to continue to be broadly described as a psychological account.

On McMahan's embodied mind account, identity-determining prenatal injuries are far less likely to occur, but they are still possible. Again, the issue implies that the most serious prenatal injuries do not harm, while those that are less serious do, which seems absurd.

I conclude that the non-identity problem for prenatal injury poses considerable difficulties for the standard psychological account of personal identity, Williams' account and variants such as McMahan's embodied mind account. When comparing accounts of personal identity, this should be considered an important factor that weighs heavily against the coherence of psychological accounts and supports accounts that fix identity at conception.

Open Access This article is licensed under a Creative Commons Attribution 4.0 International License, which permits use, sharing, adaptation, distribution and reproduction in any medium or format, as long as you give appropriate credit to the original author(s) and the source, provide a link to the Creative Commons licence, and indicate if changes were made. The images or other third party material in this article 
are included in the article's Creative Commons licence, unless indicated otherwise in a credit line to the material. If material is not included in the article's Creative Commons licence and your intended use is not permitted by statutory regulation or exceeds the permitted use, you will need to obtain permission directly from the copyright holder. To view a copy of this licence, visit http://creativecommons.org/licen ses/by/4.0/.

\section{References}

Boonin, D. (2008). How to solve the non-identity problem. Public Affairs Quarterly, 22(2), 129-159.

Boonin, D. (2014). The non-identity problem and the ethics of future people. Oxford University Press.

Bourget, D., \& Chalmers, D. (2014). What do philosophers believe? Philosophical Studies, 170(3), 465-500.

Congenital Disabilities (Civil Liability) Act 1976. Retrieved August 6, 2021, from https://www.legis lation.gov.uk/ukpga/1976/28/section/1

Lewis, D. K. (1986). On the plurality of worlds. Blackwell.

Lind, K., Toure, H., Brugel, D., Meyer, P., Laurent-Vannier, A., \& Chevignard, M. (2016). Extended follow-up of neurological, cognitive, behavioral and academic outcomes after severe abusive head trauma. Child Abuse \& Neglect, 51, 358-367.

McMahan, J. (2002). The ethics of killing: Problems at the margins of life. Oxford University Press.

McMahan, J. (2005). Causing disabled people to exist and causing people to be disabled. Ethics, 116(1), 77-99.

McMahan, J. (2006). Paradoxes of abortion and prenatal injury. Ethics, 116(4), 625-655.

Meacham, C. J. G. (2012). Person-affecting views and saturating counterpart relations. Philosophical Studies, 158(2), 257-287.

Parfit, D. (1987). Reasons and persons. Oxford University Press.

Rodger, D., Blackshaw, B., \& Miller, C. (2018). Beyond infanticide: How psychological accounts of persons can justify harming infants. The New Bioethics, 24(2), 106-121.

Tacca, M. C. (2011). Commonalities between perception and cognition. Frontiers in Psychology. https:// doi.org/10.3389/fpsyg.2011.00358

Wilhoit, L. F., Scott, D. A., \& Simecka, B. A. (2017). Fetal alcohol spectrum disorders: Characteristics, complications, and treatment. Community Mental Health Journal, 53, 711-718.

Williams, N. J. (2013). Possible persons and the problem of prenatal harm. Journal of Ethics, 17(4), $355-385$.

Wolf, C. (2009). Do future persons presently have alternate possible identities? In Harming future persons (pp. 93-114). Springer

Wrigley, A. (2012). Harm to future persons: Non-identity problems and counterpart solutions. Ethical Theory and Moral Practice, 15(2), 175-190.

Publisher's Note Springer Nature remains neutral with regard to jurisdictional claims in published maps and institutional affiliations. 